\title{
Prevalence of Orthostatic Hypotension in the Elderly in Anambra State
}

\author{
Enwonwu Kenechukwu', Ibeh Christian ${ }^{1}$, Modebe Ifeoma ${ }^{1}$, Owoaje Emeh $^{2}$, Ayuba Zoakah ${ }^{3}$, \\ Ifeadike Chigozie $^{1}$, Ezeama Nkiru ${ }^{1}$, Azuike Emmanuel ${ }^{1}$ \\ ${ }^{1}$ Department of Community Medicine, NnamdiAzikiwe University Teaching Hospital, Nnewi, Nigeria \\ ${ }^{2}$ School of Public Health, University College Hospital, Ibadan, Nigeria \\ ${ }^{3}$ Department of Community Medicine, University of Jos, Jos, Nigeria
}

Email address:

keneokocha@ymail.com(K. Enwonwu)

\section{To cite this article:}

Enwonwu Kenechukwu, Ibeh Christian, Modebe Ifeoma, Owoaje Emeh, Ayuba Zoakah, Ifeadike Chigozie, Ezeama Nkiru, Azuike Emmanuel. Prevalence of Orthostatic Hypotension in the Elderly in Anambra State. Science Journal of Clinical Medicine.

Vol. 7, No. 4, 2018, pp. 30-36. doi: 10.11648/j.sjcm.20180704.11

Received: September 4, 2018; Accepted: October 8, 2018; Published: November 6, 2018

\begin{abstract}
Background: Orthostatic hypotension is a condition in which blood pressure drops abnormally when a person stands up from a sitting or a lying down position. It is a sustained reduction of systolic blood pressure of at least $20 \mathrm{mmHg}$ or diastolic blood pressure of at least $10 \mathrm{mmHg}$ within three minutes of standing or a head-up tilt to at least 60 degrees on a tilt table. Orthostatic hypotension has been observed in all age groups, but it occurs more in the elderly, especially in persons who are sick and frail. The burden of Orthostatic hypotension on public health is substantial, with a prevalence of $7 \%$ to $55 \%$ in the elderly and is higher in those with risk factors. The diagnosis of orthostatic hypotension is therefore important in the treatment of elderly patients. Methods: This cross-sectional study was designed to evaluate the prevalence of orthostatic hypotension in community-dwelling elderly in Anambra State, Nigeria. The study population was a 400 persons aged 60 years and older selected by multistage sampling method. Results: The total prevalence of $\mathrm{OH}$ was $14.8 \%(\mathrm{n}=59)$. The prevalence of $\mathrm{OH}$ was related to presence of hypertension, diabetes, raised supine systolic and raised supine diastolic $\mathrm{BP}(\mathrm{P} \leq 0.05)$. Diabetics [OR: 4.689 (95\% CI: 1.121-19.984)] and those with supine diastolic hypertension [OR: 1.699 (95\% CI: 0.401-7.209)] were more likely to have $\mathrm{OH}$. Conclusion: The prevalence of orthostatic hypotension in 60 years and older adults in Anambra State was high and was found to be higher in hypertensives and diabetics.
\end{abstract}

Keywords: Blood Pressure, Orthostatic Hypotension, Elderly, Population-Based Study, Prevalence

\section{Introduction}

Normally on standing, the blood vessels in the legs constrict to prevent blood from pooling in the legs. This vascular constriction improves the return of blood to the hearts and supports blood pressure during upright posture. When this normal blood vessel constriction fails to occur efficiently, there will be a drop in blood pressure on standing. It is usually caused by excessive fall of cardiac output and defective or inadequate vasoconstrictor mechanisms [1] Symptoms of orthostatic hypotension develop on assuming the erect posture or following a head-up tilt and usually resolve on resuming the recumbent position. They include lightheadedness, dizziness, blurred vision, weakness, fatigue, nausea, palpitations, tremulousness, headache, and neck pain [1]. Orthostatic hypotension is believed to be an important cause of generalized cerebral hypoperfusion leading to dizziness, syncope, and falls [2]. It may be a cause of focal cerebral hypoperfusion as manifested by transient ischemic attacks and may also be predictive of Ischaemic stroke [3].

Orthostatic hypotension has been observed in all age groups, but it occurs more in the elderly, especially in persons who are sick and frail [3]. Older patients show several changes in the complex autonomic regulation of blood pressure as part of the adaptations related to ageing. Older people are prone to the autonomic dysfunctions induced by chronic illnesses such as diabetes, Parkinson's disease or pure autonomic failure and the use of several 
medications like anti-hypertensive drugs is also common. Orthostatic hypotension is associated with significant morbidity in $30-50 \%$ of elderly persons with known risk factors, including age, medications like antihypertensives and certain diseases like diabetes [4]. The problem of orthostatic hypotension has until recently been almost exclusively associated with cerebrovascular diseases [5] but it also appears to be a common finding even in elderly persons without apparent organic disabilities [6].

As people age, the cardiovascular reflexes responsible for vasoconstriction on standing become less able to react quickly. Aging brains are also more susceptible to the effects of lower blood pressure [7]. The older someone is, the more sensitive to the lack of blood flow and oxygen to the brain. It can be anticipated that with the expanding older population and longer survival of people with chronic disease, the prevalence of $\mathrm{OH}$ may increase. The diagnosis of $\mathrm{OH}$ is significant: $\mathrm{OH}$ may underlie symptoms of cerebral hypoperfusion and may as well be a risk factor for falls, subsequent fractures and potential morbidity [8] leading to functional impairment, hospitalization and deleterious effects on functional activities of daily living, quality of life and increase in disability status in the elderly [9]. The presence and effects of co-existing disease states also increases the prevalence of orthostatic hypotension and its complications and this further reduces the quality of life in the elderly [10]. The diagnosis of orthostatic hypotension is therefore important for the treatment of elderly patients. Thorough knowledge about orthostatic hypotension in the elderly is important in proper assessment and treatment of the elderly by clinicians which will aid improvement of patient independence and functionality.

In the literature, the prevalence of orthostatic hypotension varies greatly, depending on the population studied. Orthostatic hypotension is said to be highly prevalent in older people. In normal elderly subjects, the prevalence of orthostatic hypotension is reported to be between 4 and $33 \%$ [2]. A review of publications in Pub Med from 1980 to May 2011 [11] showed that prevalence of orthostatic hypotension varied according to the characteristics of the subject, the settings of the study and the procedure of blood pressure measurements. It was also said to be associated with several geriatric problems; gait disorders, balance disorders, falls, cerebral hypoperfusion, transient ischemic attack, cognitive impairment, acute myocardial infarct and systolic hypertension. Only original studies were considered for analysis in this review. The prevalence of asymptomatic orthostatic hypotension is much higher than most clinicians would expect. A recent study of hypotension unawareness highlights this in patients with autonomic failure [12], though the criteria used to measure orthostatic hypotension was not within the approved definition of $\geq 20 \mathrm{mmHg}$ fall in systolic blood pressure, they used $>60 \mathrm{mmHg}$ fall. The condition of orthostatic hypotension in older patients is another example of a multifactorial genetic syndrome similar to delirium. In a hospital based study in Melbourne [13], Australia, on prevalence, associations, and risk factors for orthostatic hypotension in medical, surgical, and trauma inpatients, over all prevalence was found to be $23.7 \%$ though the sample size was 76 .

Orthostatic hypotension was implicated as a cause of syncope in $24 \%$ of patients presenting in emergency department of a primary and tertiary care hospital in Cantonal Switzerland [14]. This was a prospective study and the patients were followed up for 18 months but the blood pressure in this study was measured for up to ten minutes which is not in keeping with the definition of orthostatic hypotension. The prevalence of orthostatic hypotension in a study done in Taiwan [15], was found to be $15.9 \%$ among community dwellers 20 years and above and the prevalence increased with age. The findings in this study was same as that in a Korean study [16] done on a population with an age range of 40 years to 69 years which found prevalence in adults aged $40-44$ years to be $6.4 \%$ and those 65 to 69 years as $23.1 \%$. These two studies $[15,16]$ showed that there was an increase in prevalence of orthostatic hypotension as age increased, so there was a higher prevalence of orthostatic hypotension in elderly individuals.

A restrospective study [9] in Israel on the influence of orthostatic hypotension on mortality among elderly patients discharged from an acute geriatric ward reported that prevalence of orthostatic hypotension was $34.2 \%$ in people 60 years and above in keeping with the findings in other studies. This was a hospital based prospective study with a $6 \%$ attrition rate and the prevalence of $\mathrm{OH}$ is higher with the sick and frail elderly. Data from a study [17] done to determine the prevalence of orthostatic hypotension in healthy, community-living, elderly individuals in contrast to those with known risk factors for the condition, showed prevalence for the entire population as $10.7 \%$. In the group with risk factors, the prevalence was $13.7 \%$ and $6.4 \%$ in the group without risk factors [17]. Another study [18] in Israel on elderly people 60 years and above who were admitted to an acute geriatric ward during a 2-year period to estimate the prevalence of BP changes among elderly in-patients found prevalence of $\mathrm{OH}$ to be $39.2 \%$ and $18.5 \%$ for those who had a systolic blood pressure drop of between 10 to $19 \mathrm{mmHg}$. This shows that there is an increased risk of developing orthostatic hypotension in those with delayed orthostatic hypotension (a fall in blood pressure on standing that occurs after the crucial three-minute cut off point) [1]. The prevalence of orthostatic hypotension in a communitydwelling elderly population enrolled in a cardiovascular health study [2], in Tennessee was relatively high: $16.2 \%$ for asymptomatic orthostatic hypertension and $18.2 \%$ when symptomatic orthostatic hypotension was included.

The first study that examined the epidemiology of orthostatic hypotension among hospitalized patients in USA [19], found that orthostatic hypotension-related hospitalization rates increased exponentially with age and were consistently higher in elderly males compared with females. Also the burden of orthostatic hypotension in geriatric wards and elderly community dwellers had prevalence of $68 \%$, and $6 \%$ respectively. The high prevalence of orthostatic hypotension among institutionalized patients 
likely reflects the presence of multiple risk factors such as neurodegenerative diseases known to cause orthostatic hypotension and the utilization of vasoactive medications that may impair proper response to postural changes [17]. There is currently no known study done in Africa on the prevalence of orthostatic hypotension in the elderly but studies have been done on the prevalence of orthostatic hypotension in medically ill patients. A cohort of diabetics were studied in Enugu on the frequency and pattern of cardiovascular autonomic neuropathy (CAN) in type 2 (diabetes mellitus) DM patients which had a prevalence of $3.9 \%$ [20], though the study was hospital based and the sample size was small (70). Another hospital based study done in type 1 diabetes clinic in Lagos found the prevalence to be $46.2 \%$ [21] but also had a small sample size (26) which can affect the generalizability of the study. The prevalence of orthostatic hypotension was also found to be $23.3 \%$ [22], among Diabetes mellitus patients in a diabetes clinic in Enugu, South East Nigeria with a small sample size of 70 .

\section{Methods}

\section{STUDY AREA}

This study was conducted in Anambra State, South Eastern region of Nigeria.

\section{SAMPLING TECHNIQUE}

The study was a community based cross-sectional study done through a multistage sampling method.

\section{DATA COLLECTION}

Data was collected with the aid of an intervieweradministered semi- structured questionnaire. Anthropometric data (weight, height) was obtained using weighing scale and stadiometer. Random blood sugar was measured using glucometer. Blood pressures was measured with a mercury sphygmomanometer following a standardized protocol by The Seventh Report of the Joint National Committee on Prevention, Detection, Evaluation, and Treatment of High Blood Pressure [23]. Supine measurements were taken after at least 5 minutes of rest in the supine position on the health centre examination couch. Standing measurements were taken at 0 and 2 minutes after standing. BP measured at 0 minutes was taken at the moment after rising from the supine to standing positions (usually within 15 seconds from the last supine measurement).

\section{ANALYSIS}

Data analysis was done using Statistical Package for the Social Sciences (SPSS) software version 21. The prevalence of orthostatic hypotension among the elderly patients was calculated, and also the prevalence in diabetics and hypertensives. The means of the supine and standing systolic and diastolic blood pressure of participants with and without orthostatic hypertension were compared with the one sample t-test. The differences between the mean seated and mean erect systolic blood pressure of participants with and without orthostatic hypertension was compared with the paired t-test. A p-value of $\leq 0.05$ was considered statistically significant.

Ethical clearance was obtained from ethics committee of the Nnamdi Azikiwe University Teaching Hospital Ethical
Committee (NAUTHEC). A written informed consent was obtained from the participants after a detailed explanation of the procedures involved. Those that could not read or write, thumb printed. Confidentiality was assured by not using names but numbers and participation was voluntary. They could withdraw verbally. Permission to conduct the study was sought for and obtained from Traditional rulers and the Officials of the town unions. We wish to point out the following limitations in this study: The prevalence of orthostatic hypotension is higher in the sick and frail who were excluded from the study because of inability to stand on their own.

Blood pressure was taken only once during the day. Literature indicates that $\mathrm{OH}$ varies over the course of the day.

\section{SAMPLE SIZE}

Sample size was determined using the formula for sample size determination in a finite population [23].

$$
\mathrm{n}=\mathrm{z}^{2} \mathrm{p}(1-\mathrm{p}) / \mathrm{e}^{2}
$$

Where:

$\mathrm{n}=$ Minimum sample size when target population $>10,000$

$\mathrm{Z}=$ Standard normal deviate at $95 \%$ confidence interval $=$ 1.96

$\mathrm{p}=$ prevalence of orthostatic hypotension in community dwelling elderly in Finland [24] $=34 \%$

$\mathrm{e}=$ degree of accuracy desired $=0.05$

$\therefore \mathrm{n}=1.96^{2}$ X $0.34(1-0.34) / .05^{2}$

$$
=344.8
$$

$\mathrm{n}=345$

Sample size is 345 .

Anticipating a non-response rate $(f)$ of $10 \%$, the adjusted sample size to be selected $\left(\mathrm{n}_{s}\right)$

$$
\begin{aligned}
& =\frac{n}{1-f} \\
& =345 / 1.0-0.1=383.3 \approx 384 \\
& \therefore \mathrm{n}=384
\end{aligned}
$$

\section{Results}

Table 1. Demographic characteristics of the study population.

\begin{tabular}{lll}
\hline Characteristics & Frequency & Percentage (\%) \\
\hline Sex & & \\
Male & 191 & 47.7 \\
Female & 209 & 52.3 \\
Total & 400 & 100.0 \\
Age & & \\
$60-64$ & 99 & 24.7 \\
$65-69$ & 82 & 20.5 \\
$70-74$ & 89 & 22.3 \\
$75-79$ & 62 & 15.5 \\
$80+$ & 68 & 17.0 \\
Total & 400 & 100.0 \\
Mean (SD); 70.62 (7.967) & & \\
Occupation & & \\
Active trader & 79 & 19.7 \\
Retired trader & 55 & 13.8 \\
Active civil servant & 2 & 0.5 \\
Retired civil servant & 35 & 8.8 \\
Active farmer/artisan & 132 & 33.0 \\
Retired farmer/artisan & 97 & 24.2 \\
Total & 400 & 100.0 \\
\hline
\end{tabular}


The socio-demographic characteristics of the respondents in all the eight towns is shown in table 1 . There were more females $209(52.3 \%)$ than males $191(47.7 \%)$ in the study population. The study population has a mean age of $70.62 \pm$ 7.967. The age group 60 to 64 years were the most 99 $(24.7 \%)$ and they were mostly active farmer/artisans-132 $(33.0 \%)$.

Table 2: Out of the 400 people enrolled in this study, 59 had orthostatic hypotension. The prevalence of orthostatic hypotension in this study population was $14.8 \%$.

Table 2. Prevalence of orthostatic hypotension in the study population.

\begin{tabular}{lll}
\hline Characteristics & Frequency & Percentage (\%) \\
\hline $\mathrm{OH}$ & 59 & 14.8 \\
$\mathrm{NOH}$ & 341 & 85.2 \\
Total & 400 & 100 \\
\hline
\end{tabular}

$\mathrm{OH}$ - with orthostatic hypotension

$\mathrm{NOH}$ - without orthostatic hypotension

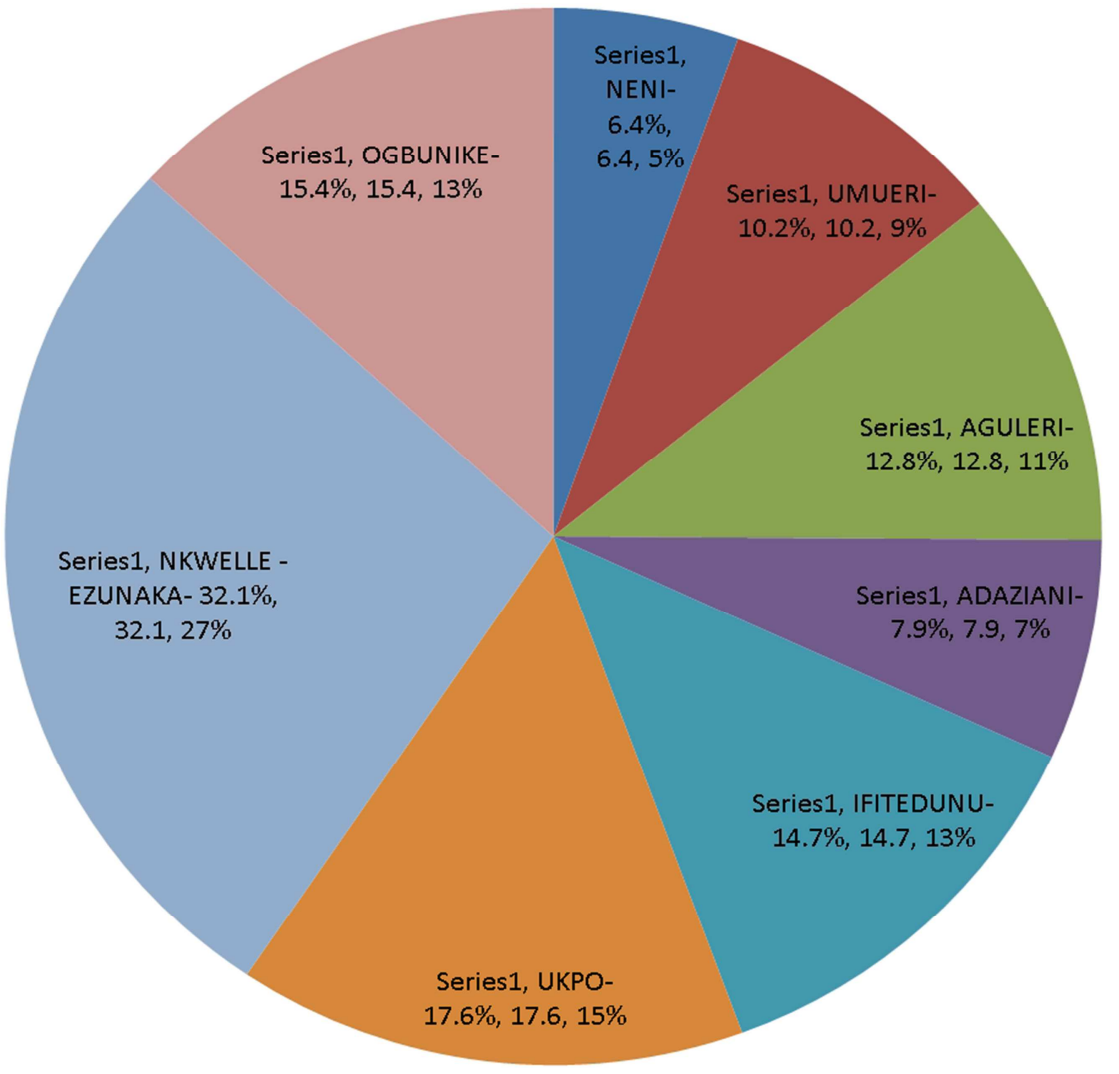

Figure 1. Prevalence of orthostatic hypotension by location.

Figure 1: Nkwelle- ezunaka had the highest prevalence (32.1\%) while Neni had the lowest (6.4\%).

Table 3. Odds ratios of OH with hypertension, diabetes, supine systolic and supine diastolic hypertension.

\begin{tabular}{|c|c|c|c|c|c|}
\hline \multirow{2}{*}{ Variables } & $\mathbf{O H}$ & NOH & \multirow{2}{*}{ OR } & \multirow{2}{*}{$95 \% \mathrm{CI}$} & \multirow{2}{*}{ P-value } \\
\hline & $\mathrm{N}=59(\%)$ & $N=341(\%)$ & & & \\
\hline Hypertensives & $56(94.9)$ & $287(84.2)$ & 0.801 & $.406,13.984$ & .027 \\
\hline Diabetics & $6(10.2)$ & $84(24.6)$ & 4.689 & $1.121,19.610$ & .012 \\
\hline Hypertensive Diabetics & $5(8.5)$ & $71(20.8)$ & 2.840 & $1.095,7.364$ & .032 \\
\hline SSTHT & $54(91.5)$ & $242(71.0)$ & .931 & $.084,10.327$ & .001 \\
\hline SDTHT & $48(81.3)$ & $125(36.6)$ & 1.699 & $.401,7.209$ & .000 \\
\hline
\end{tabular}

SSTHT - supine systolic hypertension SDTHT - supine diastolic hypertension

In table 3 diabetics were about 5 times more likely to have $\mathrm{OH}$ than non diabetics (OR:4.689, CI:1.121-19.610, p = 0.012 ), those with both hypertension and diabetes were about 3 times more likely to have $\mathrm{OH}$ than those without (OR:2.840, CI:1.095-7.364, $\mathrm{p}=0.032$ ) and those with supine diastolic hypertension were about 2 times likely to have $\mathrm{OH}$ than those without supine diastolic hypertension (OR:1.699, CI:0.401-7.209, $\mathrm{p}=0.000)$.

\section{Discussion}

Orthostatic hypotension is described as a common disorder in the elderly, particularly in the acute medical setting. Results from this study showed the prevalence of orthostatic hypotension in community dwelling elderly aged 60yrs to $98 y r$ in Anambra State. Orthostatic hypotensionwas found in 
$14.8 \%$ of this elderly population. Studies reveal that the prevalence of orthostatic hypotension varies greatly, depending on the population studied and several methodological factors. In normal elderly subjects, like those in the present study, the prevalence of orthostatic hypotension is reported to be between 4 and $34 \%$ in studies done in the USA [2] among community dwelling non institutionalised persons 65years and older, and among a random sample of persons aged 75 years and older in the City of Kuopio, Finland [24] The findings from this study is consistent with it. This may be due to the high percentage of hypertensives $(85.7 \%)$ in the study population and hypertension being a risk factor for orthostatic hypotension. Previous studies [2, 3, 4] have shown an increase in the prevalence of orthostatic hypotension with advancing age. This trend was not found in our study population aged 60 years and older $(\mathrm{P}=0.402)$, though those in age group 60 to 64 were the most $(27.1 \%)$ among those with $\mathrm{OH}$, followed by those in age group 65 to $69(23.7 \%)$, age group 75 to 79 $(20.3 \%)$, age group 80 and above $(15.3 \%)$ and age group 70 to $74(13.6 \%)$.

The findings was consistent with the study [17] done among community-dwelling elderly in the USA, who visited a senior citizen health screening programme and found no relationship between orthostatic hypotension and age. In contrast, in a cardiovascular heart study [2] done in the USA on men and women 65years and above found increase in prevalence of $\mathrm{OH}$ to be associated with increase age in their bivariate analysis but age was not found to be a predictor of $\mathrm{OH}$ in their multivariate analysis. Rutan et al [2] concluded that increased risk of $\mathrm{OH}$ may not be a normal aspect of ageing but appears associated because older people have higher prevalence of conditions that are related to $\mathrm{OH}$. Gender differences in orthostasis have been described but the mechanism involved are still uncertain. It has been reported that women are more susceptible to orthostatic intolerance following spaceflight [25] and after head down tilt experiments [26]. Though studies have shown that gender difference in cardiovascular regulation induce lower tolerance in women [27] but this present study showed that there is no statistically significant difference in gender between those who have and those who do not have $\mathrm{OH}$. This shows that there was no difference in the prevalence of $\mathrm{OH}$ between men and women and this is consistent with other studies [24]. The Study [28], done among 12 men and 8 women in centre for human aerospace in Texas concluded that though orthostatic response was more frequent in women than in men, it is not specifically gender dependent. At Johnson's space centre USA, the study [29], done on Astronaut corps - 30 men and 5 women, also concluded that women are more susceptible to orthostatic stress due probably to the presence of oestrogen (all the women were premenopausal) and its effect on vascular functions, their smaller body size and muscle mass, though these studies [28, 29] had small sample sizes.

Studies [31, 32, 34] have shown that hypertension is a risk factor for $\mathrm{OH}$ and our study demonstrated similar results.
There were $343(85.7 \%)$ hypertensives, $56(16.3 \%)$ of them had orthostatic hypotension. There was statistically significant difference between hypertensives with $\mathrm{OH}$ and non hypertensives with $\mathrm{OH}$. The results also revealed that among those found to have orthostatic hypotension, 91.5\% had supine systolic hypertension and $81.3 \%$ had supine diastolic hypertension while those with supine diastolic hypertension were about 2 times more likely to have $\mathrm{OH}$ than others (OR - 1.699). This is in keeping with findings from studies done in Taiwan [15] and Boston [32] that showed higher prevalence of $\mathrm{OH}$ among those with hypertension and especially in those with supine hypertension. The association between Diabetes mellitus and $\mathrm{OH}$ was statistically significant in our study and diabetes was found to an independent risk factor for orthostatic hypotension and the diabetics were about 5 times more likely to have $\mathrm{OH}$ than those without (OR- 4.689). The presence of comorbidity (hypertensive diabetics) had a statistically significant association with having $\mathrm{OH}$ and hypertensive diabetics were found to be about 3 times more likely to have $\mathrm{OH}$ than others without (OR - 2.840). This shows that having both diabetes and hypertension is an independent risk factor for $\mathrm{OH}$. These findings are also consistent with previous studies [35, 36, 38]. A study done in Pakistan [35] among admitted adult diabetic patients with ages between 20 and 70 years found the prevalence of $\mathrm{OH}$ to be $26 \%$. A 10-year follow-up retrospective analysis of data collected from the outpatients of Diabetology office in Slovakia [36] on Orthostatic hypotension in diabetic patients found that diabetes mellitus (both type 1 and type 2) was positively associated with the presence of $\mathrm{OH}$. The study done among diabetics in Japan [37] found prevalence of $\mathrm{OH}$ to be $7 \%$ and their multivariate analysis also revealed that the association remained significant after adjustment for the treatment and duration of diabetes, age, sex and body mass index. The study done in Morocco [39] to determine if $\mathrm{OH}$ is more prevalent in hypertensive diabetics than in normotensive diabetics, $\mathrm{OH}$ was found in $42.3 \%$ of hypertensive diabetics while $13.6 \%$ of normotensive diabetics had $\mathrm{OH}$ with a statistically significant association.

\section{Conclusion and Recommendation}

The prevalence of orthostatic hypotension in 60 years and older adults in Anambra State was high and was found to be higher in hypertensives and diabetics. Hypertension, supine systolic BP, supine diastolic BP, supine systolic hypertension and supine diastolic hypertension were significantly associated with $\mathrm{OH}$ and diabetes and supine diastolic hypertension were independent risk factors of $\mathrm{OH}$. The need for testing $\mathrm{OH}$ in patients aged 60 years and older regardless of the BP levels in a supine position so as to prevent falls and other problems associated with $\mathrm{OH}$ in the elderly is highly recommended. Elderly persons with hypertension or diabetes mellitus should receive regular monitoring of supine and upright blood pressure in order to detect orthostatic hypotension and prevent its complications. 


\section{References}

[1] Enrique AL, Andrea AC, María de los Angeles C, Karla LC, Pablo ED. Prevalence of orthostatic hypotension in a series of elderly Mexican institutionalized patients. Cardiol J. 2011; 18 (3): $282-288$.

[2] Rutan GH, Hermanson B, Bild DE, Kittner SJ, LaBaw F, Tell GS. Orthostatic hypotension in older adults. The Cardiovascular Health Study. CHS Collaborative Research Group. Hypertension. 1992; 19:508-19.

[3] Judd E, Calhoun DA. Hypertension and orthostatic hypotension in older patients. J Hypertens (Los Angel). 2012; $30(1): 38-39$.

[4] Mader SL. Identification and Management of Orthostatic Hypotension in Older and Medically Complex Patients. Expert Rev CardiovascTher. 2012; 10 (3):387-395.

[5] Avraham W, Ehud G, Yichayaou B, Joseph G. Orthostatic Hypotension in Acute Geriatric Ward. Is It a Consistent Finding? Arch Intern Med. 2002; 162 (20):2369-2374.

[6] Baliga R, Prabhu G. Orthostatic hypotension in healthy elderly: Is it a myth? N Am J Med Sci. 2010; 2 (9):416-418.

[7] Henricks M, Cutler M. Essential Facts About Orthostatic Hypotension. [Internet]. [Updated Sept 17 2015]. [Cited $\begin{array}{llll}\text { March } & 14 & 2016] . & \text { Available }\end{array}$ from:http//www.everydayhealth.com/news/essential-factsabout-orthostatic-hypotension.

[8] Platts SH, Bairey CN, Barr Y, Qi F, Martha G, Hughson R. Effects of Sex and Gender on Adaptation to Space: Cardiovascular Alterations. Res J Womens Health 2014; 23 (11):950-955.

[9] Weiss A, Beloosesky Y, Kornowski R, Yalov A, Grinblat J, Grossman E. Influence of Orthostatic Hypotension on Mortality Among Patients Discharged from an Acute Geriatric Ward. J Gen Intern Med. 2006; 21 (6):602-606.

[10] Angelousi A, Girerd N, Benetos A. Association between orthostatic hypotension and cardiovascular risk, cerebrovascular risk, cognitive decline and falls as well as overall mortality: a systematic review and meta-analysis. J Hypertens 2014; 32:1562-1571.

[11] Pepersack T, Gilles C, Petrovic M, Spinnewine A, Baeyens H, Beyer I et al. Prevalence of orthostatic hypotension and relationship with drug use amongst older patients. ActaClinBelg. 2013; 68 (2):107-12.

[12] Hirai FE, Moss SE, Klein BEK, Klein R. Postural Blood Pressure Changes and Associated Factors in Long-Term Type 1 Diabetes: Wisconsin Epidemiologic Study of Diabetic Retinopathy. J Diabet Complications. 2009; 23 (2):83-88.

[13] Aung, A K, Corcoran S J, Nagalingam V, Paul E, Newnham $\mathrm{H}$ H. Prevalence, Associations, and Risk Factors for Orthostatic Hypotension in Medical, Surgical, and Trauma Inpatients: An Observational Cohort Study. The Ochsner Journal. 2012; 12 (1): 35-41.

[14] Sarasin FP, Louis-Simonet M, Carballo D, Slama S, Junod AF Unger PF. Prevalence of orthostatic hypotension among patients presenting with syncope in the ED. Am J Emerg Med.
$2002 ; 20(6): 497-501$.

[15] Wu J, Yang Y, Lu F, Wu C, Chang C. Population-based study on the prevalence and correlates of orthostatic hypotension/hypertension and orthostatic dizziness. Hypertens Res. 2008; 31 (5): 897-904.

[16] Shin C, Abbott RD, Lee H, Kim J, Kimm K. Prevalence and correlates of orthostatic hypotension in middle-aged men and women in Korea: the Korean Health and Genome Study. J Hum Hypertens. 2004; 18: 717-723.

[17] Mader SL, Josephson KR, Rubenstein LZ. Low Prevalence of Postural Hypotension Among Community-Dwelling Elderly. JAMA. 1987; 258 (11):1511-1514.

[18] Weiss A, Beloosesky Y, Kornowski R, Yalov A, Grinblat J, Grossman E. Orthostatic hypotension in the elderly: are the diagnostic criteria adequate? J Hum Hypertens. 2004; 18:301305 .

[19] Shibao C, Grijalva C, Raj SR, Biaggioni MS, Griffin M. Orthostatic Hypotension-Related Hospitalizations in the United States. Am J Med. 2007; 120:975-980.

[20] Eze C, Onwuekwe I, Ogunniyi A. The frequency and pattern of cardiac autonomic neuropathy (CAN) in type 2 DM patients in a diabetic clinic in Enugu South-East Nigeria. Niger J Med 2013; 22:24-31.

[21] Oduwole OA, Adeniyi OF, Esezebor CI, Ekure E, Fajolu IB, Renner JK. Postural hypotension in type 1 diabetes: The influence of glycemic control and duration of illness. Niger $\mathbf{J}$ ClinPract. 2014; 17 (2):140-144.

[22] Eze CO1, Onwuekwe IO, Agu CE, Kalu UA. The prevalence of orthostatic hypotension in type 2 diabetes mellitus patients in a diabetic clinic in Enugu South-East Nigeria. Niger J Med. 2013; 22 (3):175-180.

[23] Chobanian AV, Bakris GL, Black HR, Cushman WC, Green LA, IzzoJr JL et al. The Seventh Report of the Joint National Committee on Prevention, Detection, Evaluation, and Treatment of High Blood Pressure. JAMA. 2003; 289 (19):2560-2571.

[24] Araoye MO. Research Methodology with Statistics for Health and Social Sciences: Sample size determination. Nathadex publishers. Nigeria. 2004. p. 115-120.

[25] Hiitola P, Enlund H, Kettunen R, Sulkava R, Hartikainen S. Postural changes in blood pressure and the prevalence of orthostatic hypotension among home-dwelling elderly aged 75 years or older. J Hum Hypertens. 2009; 23:33-39.

[26] Kamaruzzaman S, Watt H, Carson C, EbrahimS. The association between orthostatic hypotension and medication use in the British Women's Heart and Health Study. Age Ageing. 2010; 39: 51-56.

[27] Fitzpatrick A, Theodorakis G, Vardas P. Methodology of head-up tilt testing in patients with unexplained syncope. J Am CollCardiol. 1991; 17 (1):125-30.

[28] Tyberghein M, Philips JC, Krzesinski JM, ScheenAJ. Orthostatic hypotension: definition, symptoms, assessment and pathophysiology. Rev Med Liege. 2013; 68 (2):65-73.

[29] Yu-Chien C, Aditi V, Hymen E, Perlmuter LC. Gender differences in orthostatic hypotension. Am J Med Sci. 2011; 342 (3): 221-225. 
[30] Carter III R, Hinojosa-Laborde C, Convertino VA. Sex comparisons in muscle sympathetic nerve activity and arterial pressure oscillations during progressive central hypovolemia. Physiological Reports.

[31] Naschitz, JE, Slobodin G, Elias N, Rosner I. The patient with supine hypertension and orthostatic hypotension: a clinical dilemma. Postgrad Med J. 2006; 82 (966): 246-253.

[32] Hosokawa K, Ide T, Tobushi T, Sakamoto K, Onitsuka K. Bionic Baroreceptor Corrects Postural Hypotension in Rats With Impaired Baroreceptor. Circulation. 2012; 126:12781285 .

[33] Gangavati A, Hajjar I, Quach L, Jones RN, Kiely DK, Gagnon $\mathrm{P}$ et al. Hypertension, orthostatic hypotension, and the risk of falls in a community-dwelling elderly population: the maintenance of balance, independent living, intellect, and zest in the elderly of Boston study. J Am Geriatr Soc. 2011; 59 (3):383-389.

[34] Fedorowski A, Burri P, Melander O. Orthostatic hypotension in genetically related hypertensive and normotensive individuals. J Hypertens. 2009; 27 (5):976-82.

[35] BâHamidou Oumar, MentaIchaka, Sangarélbrahima,
SidibéNoumou, DiallIlo Bella, CoulibalySouleymane et al. Orthostatic Hypotension in a Population of Hypertensive Patients in the University Hospital Gabriel Touré. Clinical Medicine Research. 2015; 4 (4): 116-119.

[36] Rahman S, Ahmad R, Aamir A H. Prevalence of orthostatic hypotension among diabetic patients in a community hospital of peshawar. Pak J Physiol. 2010; 6 (2):37-39.

[37] Gaspara L, Kruzliakb P, Komornikovaa A, Celecovaa Z, Krahuleca B, Balaza D et al. Orthostatic hypotension in diabetic patients-10-year follow-up study. Journal of Diabetes and its Complications. 2016; 30 (1):67-71.

[38] Tsutsu N, Nunoi K, Yokomizo Y, Kikuchi M, Fujishima M. Relationship between glycemic control and orthostatic hypotension in type 2 diabetes mellitus - A survey by the Fukuoka Diabetes Clinic Group. Diabetes Research and Clinical Practice. 1990; 8 (2):115-123.

[39] El Bakkali1 M, Benjelloun H, Rkain H, Coghlan L, Radjab Y, Errguig L. A Cross-Sectional Study Evaluating Orthostatic Hypotension in Normotensive and Hypertensive Patients with Diabetes Mellitus. Journal of Cardiovascular Disease. 2013; 1 (1). 